Chapter 8

\title{
Stochastic Models of Physicochemical Processes in Catalytic Reactions - Self-Oscillations and Chemical Waves in CO Oxidation Reaction
}

\author{
Vladimir I. Elokhin \\ Additional information is available at the end of the chapter
}

http://dx.doi.org/10.5772/53792

\section{Introduction}

It is well known that many processes of heterogeneous catalysis cannot be described correctly in terms of the Langmuir kinetics or, similarly, in terms of the law of surface action. As has been experimentally shown, not only phenomena related to the substantial spatial and energetic heterogeneity of the adsorbed layer [1] (restricted mobility of adsorbed species, phase transitions in the layer associated with the interaction of adsorbates on the surface, diffusion of adsorbed species into the subsurface layer resulting in the change of adsorption and catalytic properties of the surface, etc.) are very often observed in real catalytic systems, but also the rearrangement of the catalytic surface itself due to adsorption, desorption, reactions $[2,3]$, and the temperature factor (for example, the phase transition of surface roughening $[4,5])$. In several cases, the effect of different surface defects appearing during the reaction or under high-temperature conditions (terraces, steps, kinks, point defects, etc.) on catalytic transformations is the determining factor. However, despite many experimental data, theoretical methods (both deterministic and statistical) used for the description and analysis of this type of nonideal catalytic systems are presently insufficiently developed.

In our opinion, the imitation (or statistical) simulation based on the Monte Carlo method [6] is one of the most efficient tool for describing the spatio-temporal dynamics of the behavior of adsorbates on the real catalytic surface, whose structure can change during the reaction. This method makes it possible to obtain qualitatively new results [7], which cannot be obtained by traditional phenomenological models (systems of differential equations). Several advantages of the Monte Carlo method that are especially important for the solution of the above-considered problem should be mentioned: (a) possibility of independent considera- 
tion of the local environment of each adsorbed molecule or active center on the surface, (b) sufficiently simple algorithmic presentation of almost any concepts describing the processes occurring in terms of the generalized lattice gas model (including processes that cannot be described using analytical models), and (c) computer visualization of the simulated surface and adsorption layer (formation of structures, phase transitions, etc.). Possible spatio-temporal changes on the surface can be taken into account at the atomic-molecular level, which allows one to understand deeply and in detail mechanisms of heterogeneous catalytic reactions and facilitates substantially the interpretation of physicochemical experimental data.

There are some disadvantages of statistical models:

i. the dynamic behavior cannot be predicted on the basis of bifurcation analysis (this can be done by deterministic models with not too large dimensionality);

ii. it is difficult to take into account the real ratios between the rates of adsorption, reaction, and diffusion;

iii. small scales of systems under study. The two latter difficulties can be overcome by increasing of the effectiveness of simulations, or by implementation of parallel computation [8].

\section{Self-oscillations and surface waves in $\mathrm{CO}$ oxidation reaction on platinum metals}

Catalytic $\mathrm{CO}$ oxidation on platinum-group metals is a classical model reaction in heterogeneous catalysis. In addition to being of fundamental interest, this reaction is of great environmental significance as a means of removing carbon monoxide from exhaust gases. $\mathrm{CO}$ oxidation under far-from-equilibrium conditions can be accompanied by critical phenomena, such as multiple steady states, self-oscillations, traveling waves, and chaos [1, 9-18]. The successful attempts of searching for new catalytic reactions with this type of dynamic behavior resulted in the situation that presently we know more than fifty different oscillation systems [19] occurring under different experimental conditions on various types of catalysts. Various oscillation mechanisms have been discovered and investigated to date. They include surface structure transitions $[1,11]$, the formation of a "subsurface" oxygen layer [12-17], and the "explosive" interaction between adsorbed species [18]. A common feature in all these mechanisms is the spontaneous periodical transition of the metal surface from inactive to highly active catalytic state.

Use of physical methods with a high space resolution $(<1 \mu \mathrm{m})$ made it possible to study in situ the formation of traveling chemical waves arising from the oscillatory dynamics of the reaction on Pt and Pd single-crystal surfaces [16, 17]. It was demonstrated that the conventional approaches using phenomenological kinetic equations (sets of differential equations) are inappropriate for describing the nature of spatiotemporal chemical waves on the metal surface [7]. So-called kinetic (dynamic) Monte Carlo models turned out to be the most suita- 
ble. The most recent review of the application of these models to oscillatory reactions was given by Zhdanov [20]. Here, we present an overview of our Monte Carlo studies of the formation of self-oscillations and chemical waves in $\mathrm{CO}$ oxidation reaction over $\mathrm{Pt}(100)$ and $\operatorname{Pd}(110)$ single crystals, based on experimental data. The kinetic models for these surfaces differ in the detailed mechanism of the appearance of oscillations. Both models indicate oscillations of the $\mathrm{CO}_{2}$ formation rate and adsorbed species concentrations. The oscillations are accompanied by wave phenomena on the model surface.

\subsection{Pt(100): Simulation of self-oscillations and chemical waves}

The detailed reaction mechanism used in the simulation of the self-oscillations [20-24] is based on experimental data, reported earlier [11-17]. It has been revealed that the self-oscillations of the $\mathrm{CO}$ oxidation rate are related with the reversible phase transition $\mathrm{Pt}(100)$-(hex) $\leftrightarrow(1 \times 1)$. The platinum state in unreconstructed $(1 \times 1)$ phase is catalytically active because the sticking coefficient of oxygen, characterizing the probability of adsorption, is equal to $\mathrm{S}^{1 \times 1}\left(\mathrm{O}_{2}\right) \approx 0.3 \div 0.4$ on $(1 \times 1)$ phase, in contrast with $\mathrm{S}^{\text {hex }}\left(\mathrm{O}_{2}\right) \approx 0.001$.

The mechanism of the reaction can be represented as (Scheme 1):

(I) $\mathrm{CO}+* \rightarrow \mathrm{CO}_{a d s}$;

(II) $\mathrm{CO}_{\text {ads }}^{\text {hex }} \rightarrow \mathrm{CO}+*_{\text {hex }}$;

(III) $\mathrm{CO}_{\text {ads }}^{1 \times 1} \rightarrow \mathrm{CO}+*{ }_{1 \times 1}$

(IV) (hex) $\rightarrow(1 \times 1): 4 \mathrm{CO}_{\text {ads }} \rightarrow 4 \mathrm{CO}_{\text {ads }}^{1 \times 1}$;
(V) $(1 \times 1) \rightarrow($ hex $):{ }^{*}{ }_{1 \times 1} \rightarrow *_{\text {hex }}$;

(VI) $\mathrm{O}_{2}+2 *_{1 \times 1} \rightarrow 2 \mathrm{O}_{a d s}^{1 \times 1}$;

(VII) $\mathrm{O}_{a d s}^{1 \times 1}+\mathrm{CO}_{\text {ads }} \rightarrow \mathrm{CO}_{2}+*{ }_{1 \times 1}+*$;

(VIII) $\mathrm{CO}_{a d s}+* \rightarrow *+\mathrm{CO}_{a d s}$

\section{Scheme 1.}

Below, we present a brief description of the steps of this catalytic cycle. Step (I) is CO adsorption. The absence of indices at the active site $*$ means that $\mathrm{CO}$, unlike oxygen, has the same sticking coefficient $\left(\mathrm{S}_{\mathrm{CO}}\right)$ for $*_{\text {hex }}$ and $*_{1 \times 1}$. Steps (II) and (III) are CO desorption. The rate constants of $\mathrm{CO}$ desorption from the surface phases (hex) and (1x1) differ by approximately $3 \div 4$ orders of magnitude. Step (IV) is the (hex) $\rightarrow(1 \times 1)$ phase transition. In accordance with [25], it is assumed that only CO molecules adsorbed simultaneously on the four nearest neighbor sites of the model grid can cause its transformation into the (1x1) structure (with some probability). Step $(\mathrm{V})$ is the back structural transition $(1 \times 1) \rightarrow($ hex). Step $(\mathrm{VI})$ is oxygen adsorption. The dissociative adsorption of $\mathrm{O}_{2}$ takes place only on double nearest neighbor (1x1)-type sites. Step (VII) is $\mathrm{CO}_{2}$ formation. The $O_{a d s}^{1 \times 1}$ reacts with $\mathrm{CO}_{a d s}^{1 \times 1}$ and $C \mathrm{O}_{a d s}^{\text {hex }}$ at equal rates, and the kinds of active sites remain unchanged. Step (VIII) is $\mathrm{CO}_{\mathrm{ads}}$ diffusion. The adsorbed molecule $\mathrm{CO}_{\text {ads }}$ diffuses on the surface by hopping from its site to a random nearest neighbor empty site. As this takes place, the kinds of active sites remain unchanged. Along with steps (III) and (VII), diffusion (VIII) is a source of empty $*_{1 \times 1}$ active sites, which are necessary for the dissociative adsorption of oxygen. 
CO oxidation reaction on $\mathrm{Pt}(100)$ was simulated on an $\mathrm{N} \times \mathrm{N}$ grid of square cells with cyclic boundary conditions (usually, we took $N=1000$ ). The state of a cell was set according to the rules determined by the detailed reaction mechanism. The time unit was a Monte Carlo (MC) step, which consisted of $\mathrm{N} \times \mathrm{N}$ choice and realization trials of the main elementary processes (steps (I)-(VII)). The probability of occurrence of each step for the adsorption, desorption, and chemical reaction processes was taken to be equal to the ratio of the rate constant of this step to the sum of the rate constants of all steps. The rate constants of steps (I)(VII) at $T \sim 500 \mathrm{~K}$ were taken from [26, Table 1].

After selecting one of the processes (steps (I)-(VII)) and performing a realization trial, we considered the internal cycle of diffusion, which consisted of $\mathrm{M}$ diffusion trials for $\mathrm{CO}_{\mathrm{ads}}$ molecules (typically, $\mathrm{M}=50-100$ ). The $\mathrm{CO}$ oxidation rate and the reactant coverages of the surface were calculated after each $\mathrm{MC}$ step as the number of the resulting $\mathrm{CO}_{2}$ molecules (or the number of cells in the corresponding state) divided by the total number of cells, $\mathrm{N}^{2}$. The algorithm of the simulation of $\mathrm{CO}$ oxidation on $\mathrm{Pt}(100)$ is detailed elsewhere [21].

The Monte Carlo model of the reaction reveals oscillations of the reaction rate and the $\mathrm{CO}_{\text {ads }}$ and $\mathrm{O}_{\text {ads }}$ coverages of the surface and transformations between the surface phases (1x1) and (hex) under conditions similar to experimental results [21]. The oscillations, Figure 1, are accompanied by the propagation of concentration waves on the surface, Figure 2. The most noteworthy result of the simulation is the revealing of a narrow reaction zone before the front of the propagating oxygen wave, which suggests that the surface passes into a highly active catalytic state, Figure 3. It can be seen from Figures 2 and 3, that the local $\mathrm{CO}_{2}$ formation rate is the lowest in the $\mathrm{CO}_{\text {ads }}$ layer, takes an intermediate value in the $\mathrm{O}_{\text {ads }}$ layer, and is the highest in the narrow reaction zone along the perimeter of the growing $\mathrm{O}_{\text {ads }}$ islands. Note that this narrow reaction zone is observed only when there is a propagating oxygen wave. A local increase in the $\mathrm{CO}_{\text {ads }}$ concentration on the surface causes the disappearance of the narrow reaction zone, as follows from the behavior of an oxygen island (A) in the upper left corner of Fig. 2. This island disappears as its oxygen reacts with $\mathrm{CO}_{\text {ads }}$. Here, as $\mathrm{O}_{\mathrm{ads}}$ is consumed, the vacated $(1 \times 1)$ phase turns into (hex). The observed difference between the local reaction rates can be explained in terms of competitive oxygen and carbon monoxide adsorption: the $\mathrm{CO}_{\mathrm{ads}}$ layer inhibits the dissociative adsorption of oxygen, while the $\mathrm{O}_{\text {ads }}$ layer always has single vacant sites for monomolecular $\mathrm{CO}$ adsorption. The highest total reaction rate in an oscillation period is reached at the instant when the perimeter of the growing oxygen islands is the longest. At the final stage of the autooscillation cycle, the (1x1) phase turns into (hex) and the $\mathrm{CO}_{\mathrm{ads}}$ coverage increases owing to $\mathrm{CO}$ adsorption on empty sites (both on (hex) and (1x1)). The appearance of a narrow reaction zone during oxygen wave propagation was observed experimentally in $\mathrm{H}_{2}$ and $\mathrm{CO}$ oxidation on a $\mathrm{Pt}[100]$ oriented tip by atom-probe field ion microscopy with a resolution of $\sim 5 \AA$ [27] (the experimental setup is shown schematically in Fig. 3). 


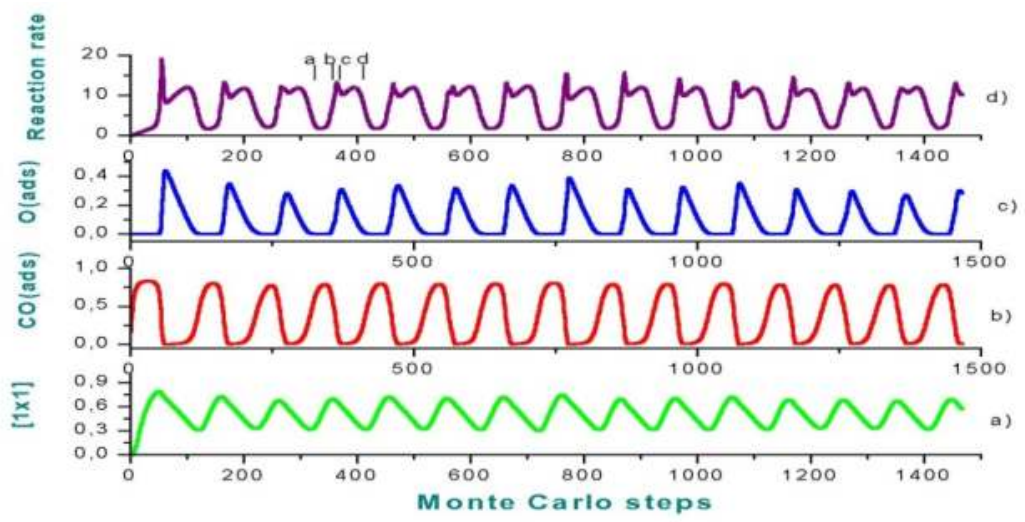

Figure 1. Self-oscillations of the model variables at $\mathrm{M}=100$ and $N=500$. a) Coverage $\left.*_{1 \times 1}=*_{1 \times 1}+C O_{a d s}^{1 \times 1}+O_{a d s}^{1 \times 1} ; b\right)$ $\left.\mathrm{CO}_{\text {ads }}=\mathrm{CO}_{a d s}^{1 \times 1}+\mathrm{CO}_{a d s}^{\text {hex }} ; \mathrm{c}\right) \mathrm{O}_{a d d s}^{1 \times 1} ;$ d) specific reaction rate. Parameter values: $\mathrm{k}_{1}=2.94 \times 10^{5} \mathrm{ML} / \mathrm{s}$ Torr, $\mathrm{P}_{\mathrm{co}}=5 \times 10^{-5}$ Torr, $\mathrm{k}_{2}$ $=4 \mathrm{~s}^{-1}, \mathrm{k}_{3}=0.03 \mathrm{~s}^{-1}, \mathrm{k}_{4}=3 \mathrm{~s}^{-1}, \mathrm{k}_{5}=2 \mathrm{~s}^{-1}, \mathrm{k}_{6}=5.6 \times 10^{5} \mathrm{ML} / \mathrm{s}$ Torr, $\mathrm{P}_{\mathrm{O} 2}=10^{-4}$ Torr, [26, Table 1].

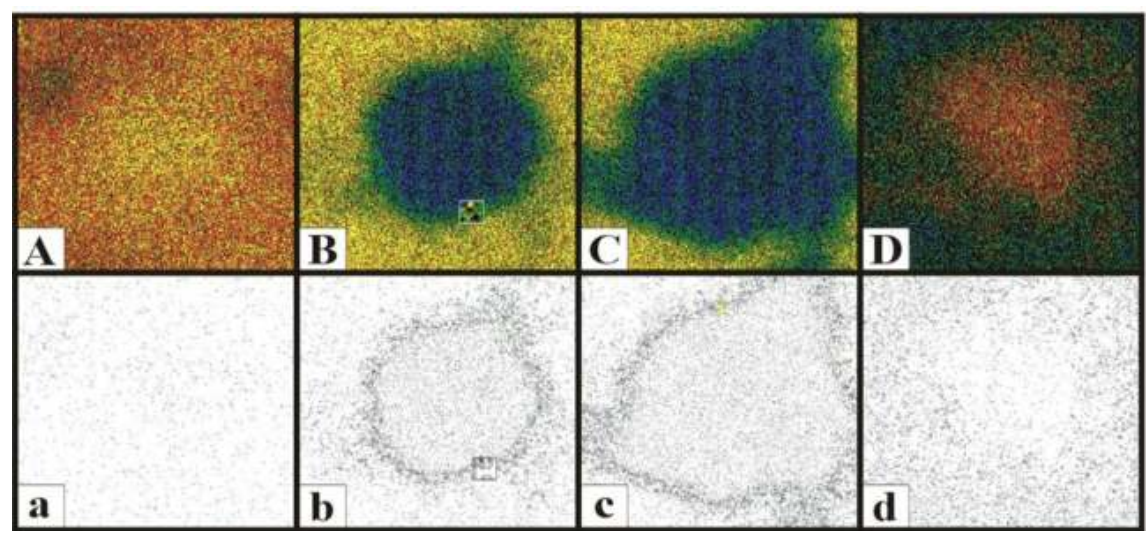

Figure 2. Snapshots reflecting the adsorbate distribution over the surface (capital letters) and the appropriate $\mathrm{CO}_{2}$ formation rate intensity (small letters). On the $A-D$ snapshots $\mathrm{O}_{\text {ads }}$ is painted blue, $\mathrm{CO}_{\text {ads }}$ on hex as red, $\mathrm{CO}_{\text {ads }}$ on $(1 \times 1)$ as yellow, empty $*_{1 \times 1}$ as green. On the a-d snapshots a grey scale reflects the rate intensity. Snapshots $A, a-D, d$ correspond to vertical bars ( $a, b, c, d)$ on the Fig.1d

Obviously, in order to synchronize the spatiotemporal changes in different areas of the surface, it is necessary to take into account the diffusion of the adsorbed species. However, the inclusion of diffusion into the set of randomly chosen main processes (in our case, steps (I)-(VII)) leads to an unreasonable increasing of the computational time because the diffusion rate constant is several orders of magnitude larger than the rate constants of the other processes. For this reason, most researchers employing kinetic Monte Carlo models in which diffusion must be taken into account consider an internal diffusion cy- 
cle, making $\mathrm{M}$ random transfer trials for the adsorbed substances (in our case, only $\mathrm{CO}_{\mathrm{ads}}$ ) after each of $\mathrm{N} \times \mathrm{N}$ realization trials of the main elementary processes. Since an increase in the diffusion cycle parameter $\mathrm{M}$ above 100 does not result in our case in quantitative or qualitative changes in the spatiotemporal dynamics of the reaction, we believe that the chosen value of the $\mathrm{CO}_{\mathrm{ads}}$ diffusion rate parameter is sufficiently large for synchronization of the local processes. Likewise, decreasing the parameter M to 50 does not break the regularity of the oscillations, but somewhat reduces the oscillation period and amplitude. A further decrease in $\mathrm{M}$ to 30 randomizes the oscillation period and amplitude. In this case, adsorbed oxygen is always present on the surface (Fig. 4) as mobile patches of various shapes [21]. A similar turbulent spatiotemporal dynamics of substances adsorbed on the $\mathrm{Pt}(100)$ surface in $\mathrm{CO}$ oxidation was observed by photoelectron emission microscopy (PEEM) and by ellipsomicroscopy for surface imaging (EMSI).
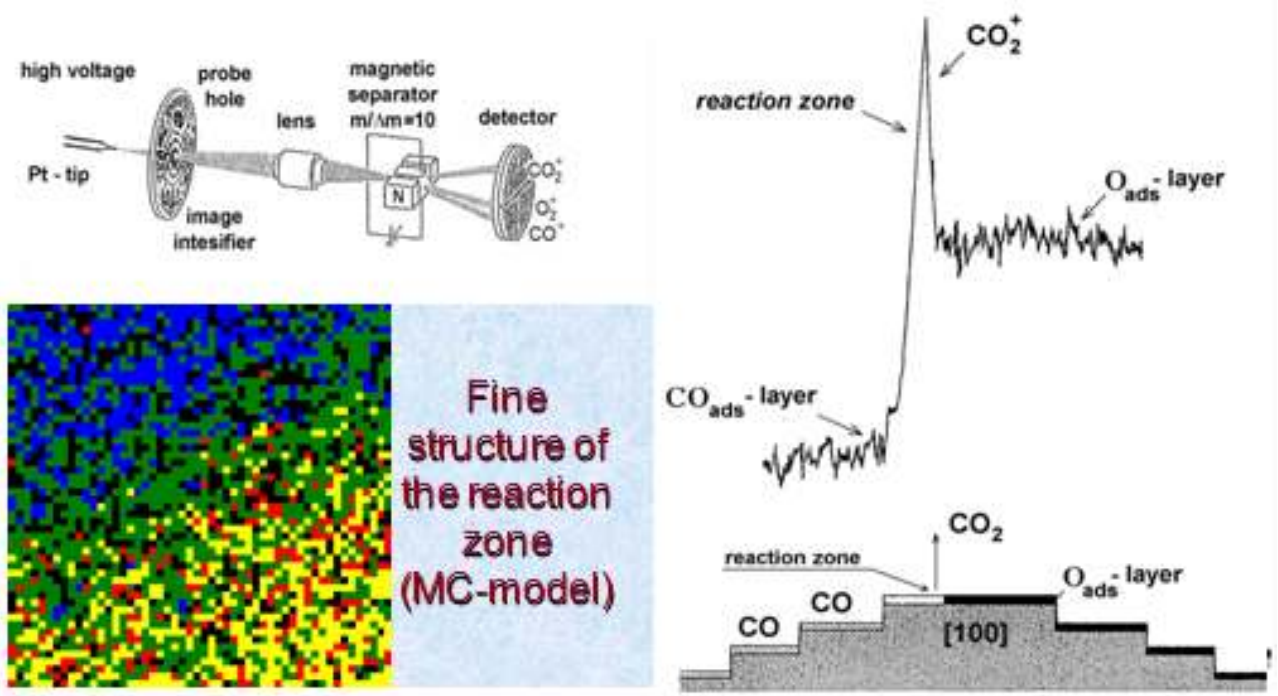

Figure 3. Experimental observation of the narrow reaction zone by means of atom-probe field ion microscopy with $5 \AA$ resolution on a platinum tip [27]. The $M C$ simulated fine structure corresponds to the enlarged inset on the Figure $2 \mathrm{~B}$.

The kinetic Monte Carlo method provides a means to study the dependence of oscillation characteristics on reaction parameters. This can be done by varying some reaction parameter (e.g., $\mathrm{CO}$ partial pressure, $\mathrm{P}_{\mathrm{CO}}$ ) from one step to another and using the surface coverage configuration calculated in the previous step as the initial condition for the next step. In this way, we found that a reaction rate and surface coverage hysteresis takes place as $\mathrm{P}_{\mathrm{CO}}$ is first raised and then decreased in the $10^{-5} \div 1.2 \times 10^{-4}$ Torr range at a fixed oxygen partial pressure of $\mathrm{P}_{\mathrm{O} 2}=2 \times 10^{-4}$ Torr [21]. At a higher $\mathrm{P}_{\mathrm{O} 2} / \mathrm{P}_{\mathrm{CO}}$ ratio, the $\mathrm{Pt}(100)$-hex surface is almost free. As $\mathrm{P}_{\mathrm{CO}}$ is raised, the $\mathrm{CO}_{\text {ads }}(1 \times 1)$ phase appears. At $\mathrm{P}_{\mathrm{CO}} \sim 3 \times 10^{-5}$ Torr, oscillations set in, whose amplitude and period increase with increasing $\mathrm{P}_{\mathrm{CO}}$. At $\mathrm{P}_{\mathrm{CO}} \sim 10^{-4}$ Torr, the surface is com- 
pletely covered by a $\mathrm{CO}_{\text {ads }}(1 \times 1)$ layer. As $\mathrm{P}_{\mathrm{CO}}$ is then decreased, the $\mathrm{CO}_{\mathrm{ads}}(1 \times 1)$ layer persists down to $\mathrm{P}_{\mathrm{CO}} \sim 5 \times 10^{-6}$ Torr because of the low probability of $\mathrm{CO}$ desorption. Therefore, it is the $\mathrm{CO}_{\mathrm{ads}}(1 \mathrm{x} 1)$ desorption constant that determined the lower limit of the hysteresis. The back transition $(1 \times 1) \rightarrow$ (hex) occurs vary rapidly (clean-off reaction [23]) via steps (V)-(VII).
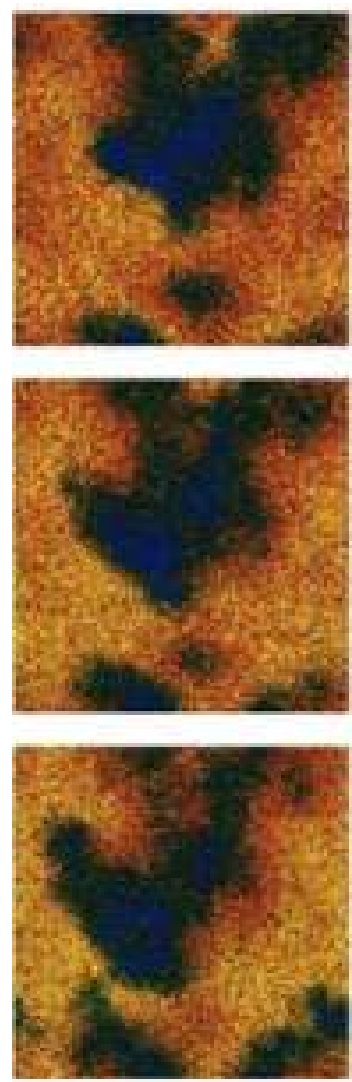
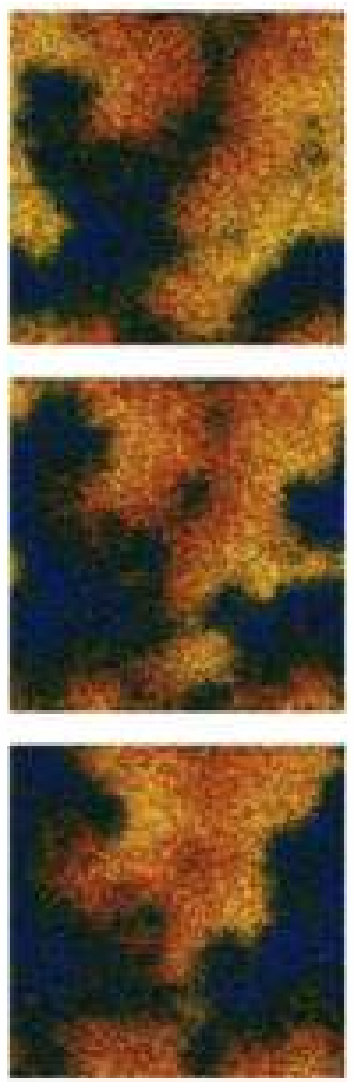
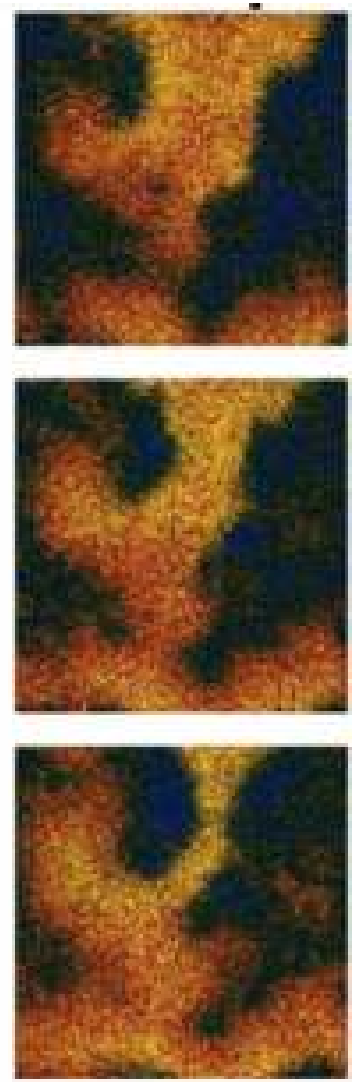

Figure 4. Snapshots reflecting the dynamics of adsorbate distribution over the surface in the case of low diffusion intensity, $M=30$. The designations of adsorbates are the same as for Figure 2 .

\section{2. $\operatorname{Pd}(110)$ : Simulation of oscillations and wave structures}

As distinct from the oscillations on the $\mathrm{Pt}(100)$ surface, which are caused by surface phase transformation, the oscillations and wave phenomena on the $\operatorname{Pd}(110)$ surface are due to merely kinetic factors, specifically, changes in the catalytic and adsorption properties of the surface, including the oxygen sticking coefficient, due to the comparatively slow formation and consumption of subsurface oxygen, $\mathrm{O}_{\text {ads }} \leftrightarrow \mathrm{O}_{\text {sub }}$. The adsorption and catalytic properties of $\mathrm{Pd}(110)$ were studied by various kinetic and physical methods [see, e.g., 28]. A reaction 
mechanism taking into account the formation of subsurface oxygen $\mathrm{O}_{\text {sub }}$ [29] was suggested to explain the observed oscillations of the $\mathrm{CO}$ oxidation rate on $\mathrm{Pt}, \mathrm{Pd}$, and $\mathrm{Ir}$. It is assumed in this mechanism that the resulting $\mathrm{O}_{\text {sub }}$ layer suppresses oxygen adsorption and favors the growth of a $\mathrm{CO}_{\text {ads }}$ layer (inactive surface) [29]. Nevertheless, the slow reaction between $\mathrm{CO}_{\mathrm{ads}}$ and $\mathrm{O}_{\text {sub }}$ removes subsurface oxygen, thus making oxygen adsorption a more favorable process (active surface). This causes $\mathrm{O}_{\text {sub }}$ formation again, so the cycle is repeated.

Based on experimental data, the following detailed mechanism of $\mathrm{CO}$ oxidation on $\operatorname{Pd}(110)$ has been formulated, which was then used in the kinetic simulation of this reaction by the Monte Carlo method [30], Scheme 2:

Initial surface $(*)$ :
(I) $\mathrm{O}_{2(\text { gas })}+2 * \rightarrow 2 \mathrm{O}_{a d s}$
(II) $\mathrm{CO}_{g a s}+* \leftrightarrow \mathrm{CO}_{a d s}$
(III) $\mathrm{CO}_{a d s}+\mathrm{O}_{a d s} \rightarrow \mathrm{CO}_{2}+2 *$

\section{Modified surface $\underline{\mathrm{O}_{\text {sub }}}$ :}

(IV) $O_{a d s}+*_{v} \rightarrow * O_{s u b}$

(V) $\mathrm{CO}_{\text {ads }}+* \mathrm{O}_{\text {sub }} \rightarrow \mathrm{CO}_{2}+2 *+*_{v}$

(VI) $\mathrm{CO}_{\text {gas }}+* \mathrm{O}_{\text {sub }} \leftrightarrow \mathrm{CO}_{a d s} \mathrm{O}_{\text {sub }}$

(VII) $\mathrm{CO}_{a d s} \mathrm{O}_{\text {sub }} \rightarrow \mathrm{CO}_{2}+*+*_{v}$

\section{Scheme 2.}

Here, $*$ and $*_{\mathrm{v}}$ are active sites of the surface and of the subsurface layer. The first step is irreversible oxygen adsorption, and the second is CO adsorption and desorption. In the third step, $\mathrm{CO}_{\mathrm{ads}}$ reacts with $\mathrm{O}_{\mathrm{ads}}$ to yield the reaction product. Subsurface oxygen, $\mathrm{O}_{\text {sub }}$ forms in the irreversible step (4). Step (5) is the slow reaction between $\mathrm{O}_{\text {sub }}$ and the nearest neighbor $\mathrm{CO}_{\text {ads }}$ molecules, which regenerates the initial active sites of the surface, $*$. The adsorbed species $\mathrm{CO}_{\text {ads }} \mathrm{O}_{\text {sub }}$ results both from $\mathrm{CO}$ adsorption from the gas phase (step (6)) and from $\mathrm{CO}_{\text {ads }}$ diffusion over active sites, both initial and modified $\left(\mathrm{O}_{\text {sub }}\right)$. The decomposition of the $\mathrm{O}_{\text {ads }} \mathrm{O}_{\text {sub }}$ complex yields $\mathrm{CO}_{2}$ and vacates the $*$ and $*_{\mathrm{v}}$ sites (step (7)). It is assumed that the heat of $\mathrm{CO}$ adsorption is lower on the modified sites $\mathrm{O}_{\text {sub }}$ than on the initial sites $*$; that is, the probability of $\mathrm{CO}_{\text {ads }} \mathrm{O}_{\text {sub }}$ desorption (step (6)) is higher than the probability of $\mathrm{CO}_{\text {ads }}$ desorption (step (2)). $\mathrm{CO}_{\text {ads }}$ can diffuse over the surface, obeying the following formal rules:

$$
\begin{gathered}
\mathrm{CO}_{\text {ads }}+^{*} \leftrightarrow{ }^{*}+\mathrm{CO}_{\text {ads }}, \\
\mathrm{CO}_{\text {ads }}+\mathrm{O}_{\text {sub }} \leftrightarrow{ }^{*}+\mathrm{CO}_{\text {ads }} \mathrm{O}_{\text {sub }}, \\
\mathrm{CO}_{\text {ads }} \mathrm{O}_{\text {sub }}+\mathrm{O}_{\text {sub }} \leftrightarrow \mathrm{O}_{\text {sub }}+\mathrm{CO}_{\text {ads }} \mathrm{O}_{\text {sub }}
\end{gathered}
$$

The shortened sequence of steps (I)-(V) [29] has frequently been used in the simulation of oscillations in catalytic oxidation reactions using either differential equations (see earlier re- 
views [13, 20]), or kinetic Monte Carlo methods [20], including our first study [31]. In our later studies [32-38], the conventional steps (1)-(5) in Scheme 2 were supplemented with the possible formation and consumption of the surface species $\mathrm{CO}_{\mathrm{ads}} \mathrm{O}_{\text {sub }}$ (steps (6) and (7)). Note that steps (6) and (7) diminish the range of existence of oscillations in the $\left(\mathrm{T}, \mathrm{P}_{\mathrm{i}}\right)$ space.

The $\operatorname{Pd}(110)$ surface was modeled as an $\mathrm{NxN}$ square grid (in our simulations, $\mathrm{N}=500-8000$ ) with periodic (sometimes, zero, i.e., nonperiodic) boundary conditions. For $\operatorname{Pd}(110)$, a cell can assume one of five states $\left(*, \mathrm{CO}_{\mathrm{ads}}, \mathrm{O}_{\mathrm{ads},}\left[\mathrm{O}_{\text {sub }}\right],\left[\mathrm{CO}_{\mathrm{ads}} \mathrm{O}_{\text {sub }}\right]\right)$ according to the rules given by the algorithm of the simulation of the detailed reaction mechanism (Scheme 2). Let us illustrate (Figure 5) the simulation algorithms, used in our simulation of CO oxidation dynamics on $\mathrm{Pd}(110)$ and $\mathrm{Pt}(100)$ ] (with some excepts connected with the realization of the stage (hex $\rightarrow(1 \times 1)$, when the four sites filled by $\mathrm{CO}_{\text {ads }}$ should be chosen for the success of the attempt) on the example of the simplified scheme, steps (I)-(V) [31].

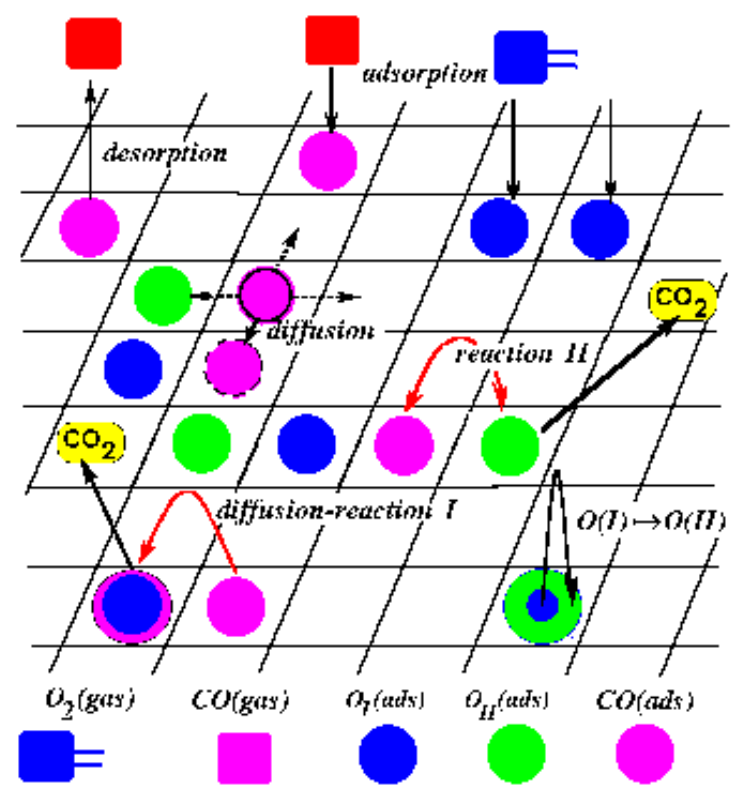

Figure 5. Schematic representation of the algorithm of the occurrence of the elementary processes on the example of shortened sequence of steps (I) - (V) [31] of the reaction mechanism (Scheme 2)

The rate coefficients $k_{i}$ were recalculated as the probability of the realization of elementary processes $\mathrm{w}_{\mathrm{i}}$ by the formula $\mathrm{w}_{\mathrm{i}}=\mathrm{k}_{\mathrm{i}} / \sum \mathrm{k}_{\mathrm{i}}$. Using a generator of random numbers uniformly distributed over the $(0,1)$ interval, we chose one of these processes according to the specified ratio of probabilities of their occurrence. Then, also using pairs of random numbers, the coordinates of one cell (or two adjacent cells, depending on chosen process) were determined from the $\mathrm{N} \times \mathrm{N}$ cells of the lattice. 
The occurrence of the chosen process was imitated as follows (see Figure 5): (1) Adsorption of $\mathrm{CO}$. The state of one arbitrarily chosen cell was checked. The free cell was occupied by adsorbed CO; when the cell was occupied, the attempt of adsorption was rejected. (2) Desorption of $\mathrm{CO}$. When $\mathrm{CO}_{\mathrm{ads}}$ was in the randomly chosen cell, it was removed from $\mathrm{CO}_{\mathrm{ads}}$ otherwise the attempt was rejected. (3) Adsorption of oxygen. The state of two adjacent randomly chosen cells was checked. When they were unoccupied, their state was changed to the state corresponding to the adsorbed oxygen. When at least one cell was occupied, the attempt of adsorption was rejected. (4) Transformation of $\mathrm{O}_{\text {ads }}$ into $\mathrm{O}_{\text {sub }}$. When oxygen of the first type was in the randomly chosen cell, the cell was transformed into the state corresponding to oxygen of the second type $\mathrm{O}_{\text {sub }}$, otherwise the attempt was rejected. The inverse transformation of $\mathrm{O}_{\text {sub }}$ into $\mathrm{O}_{\text {ads }}$ was not taken into account in this model. (5) Reaction of $\mathrm{CO}_{\text {ads }}$ with $\mathrm{O}_{\text {sub. }}$. When two randomly chosen adjacent cells contained the $\left\{\mathrm{CO}_{\mathrm{ads}}, \mathrm{O}_{\text {sub }}\right\}$ pair, the pair was removed, and one more molecule of carbon dioxide formed was put into the reaction rate counter. The reaction rate was calculated after every Monte Carlo step (MC-step) (see below) as the number of the formed $\mathrm{CO}_{2}$ molecules referred to the number of cells in the lattice. The surface coverage with the adsorbate was calculated similarly (the number of the cells occupied by the adsorbate was referred to the total number of the cells $\mathrm{N}^{2}$ ). If the required pair was not observed, the attempt was rejected. This algorithm of occurrence of elementary stages (first, choice of the process and second, choice of the cell) makes it possible to take into account the dependence of the rate of the stage on the surface coverage with the adsorbates.

After every choice of one of the aforementioned processes and an attempt to perform this process, we consider the inner cycle of the $\mathrm{CO}_{\text {ads }}$ diffusion, which included the $\mathrm{M}$ attempts of random choice of a pair of adjacent cells of the lattice. If the $\left\{\mathrm{CO}_{\mathrm{ads},} *\right\}$ pair turned out to be this pair, $\mathrm{CO}_{\text {ads }}$ and $*$ in these cells interchanged their cells, i.e., diffusion took place.

The so-called MC-step consisting of NxN attempts of choice and occurrence of main elementary processes is used as the time unit in Monte Carlo models. During the step, each cell of the lattice is addressed, on average, once. Knowing the flows of reagents per surface unit (partial pressures and lattice sizes), one can go from MC-steps to the real time.

The oscillatory behavior of $\mathrm{CO}$ oxidation on $\mathrm{Pd}(110)$, which takes place via the detailed mechanism presented in Scheme 2, was revealed by computational experiments [30] using the following set of rate constants of the elementary steps $\left(\mathrm{s}^{-1}\right)$ :

\begin{tabular}{ccccccccc}
\hline $\mathbf{k}_{\mathbf{1}}$ & $\mathbf{k}_{\mathbf{2}}$ & $\mathbf{k}_{-\mathbf{2}}$ & $\mathbf{k}_{\mathbf{3}}$ & $\mathbf{k}_{\mathbf{4}}$ & $\mathbf{k}_{5}$ & $\mathbf{k}_{\mathbf{6}}$ & $\mathbf{k}_{-\mathbf{6}}$ & $\mathbf{k}_{\mathbf{7}}$ \\
\hline 1 & 1 & 0.2 & "infin" & 0.03 & 0.01 & 1 & 0.5 & 0.02 \\
\hline
\end{tabular}

Table 1.

The oscillations are accompanied by the wavelike propagation of adsorbed species over the surface. A dramatic increase in the reaction rate takes place at the minimum $\mathrm{O}_{\text {sub }}$ concentration value within one oscillation period simultaneously with the removal of the $\mathrm{CO}_{\text {ads }}$ layer 
and with the filling of the surface by adsorbed oxygen (Figure 6). Once the maximum reaction rate is achieved, a redistribution of adsorbed oxygen occurs: $\mathrm{O}_{\text {ads }} \rightarrow \mathrm{O}_{\text {sub }}$. The position of the $\mathrm{O}_{\text {sub }}(t)$ peak determines the point at which the reaction rate begins to decrease. $\mathrm{CO}_{\mathrm{ads}}$ accumulate on the surface, and this is accompanied by the removal of the $\mathrm{O}_{\text {ads }}$ layer. When the reaction rate is the lowest, the $\mathrm{CO}_{\text {ads }}$ molecules react slowly with $\mathrm{O}_{\text {sub }}$. A decrease in the $\mathrm{O}_{\text {sub }}$ concentration to some critical values recreates the conditions necessary for subsequent $\mathrm{O}_{\text {ads }}$ adsorption, so the selfoscillation cycle is repeated. As the oxygen wave front propagates, there is a narrow reaction zone in the front of oxygen wave front enriched by empty active sites and with a local maximum of the $\mathrm{CO}_{2}$ formation rate.

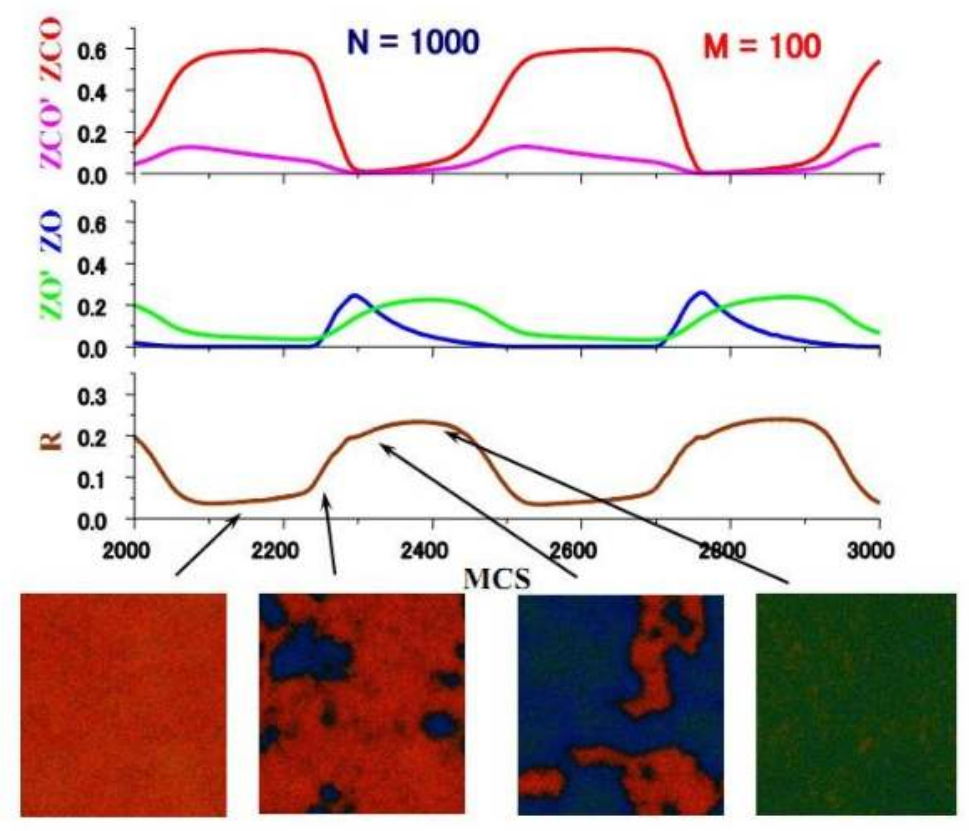

Figure 6. Reaction rate and coverages of surface species along with simulated snapshots displaying spatial distribution of different adsorbates over the surface at specific instants of time. $\mathrm{O}_{\text {ads }}$ is painted blue, $\mathrm{O}_{\text {sub }}$ as green, $\mathrm{CO}_{\text {ads }}$ as red, empty Pd sites as black.

Oxygen or $\mathrm{CO}$ adsorption on $\mathrm{Pd}(110)$ (Scheme 2, steps (1) and (2)) causes surface reconstruction into a so-called missing row structure, $\operatorname{Pd}(110)-(1 \times 1) \rightarrow(1 \times 2)$ (Figure 7$)$, and this is not accompanied by any change in the adsorption or catalytic properties of the surface. But the surface anisotropy is observed here: $\mathrm{CO}_{\text {ads }}$ molecules diffuse more rapidly along metal atom rows than in the transverse direction. We demonstrated [37] that, if this effect is taken into account in the Monte Carlo model of the reaction, then varying the $M_{x} / M_{y}$ ratio $\left(M_{x}\right.$ is the number of $\mathrm{CO}_{\mathrm{ads}}$ diffusion trials in the direction $x$, which coincides with the direction [110] on the $\mathrm{Pd}(110)-(1 \times 2)$ surface, and $\mathrm{M}_{\mathrm{y}}$ is the number of $\mathrm{CO}_{\text {ads }}$ diffusion trials in the direction $y$, 
with the total diffusion rate in the internal cycle remaining invariable: $M_{x}+M_{y}=M$ ) will not change the dependences of the reaction rate and adsorbed species coverages on time (number of MC steps), Figure 8. But the propagation of surface oxygen waves on the $\operatorname{Pd}(110)$ (1x2) surface is substantially anisotropic and the elliptic shape of oxygen waves depends on $M_{x} / M_{y}$. As the ratio $M_{x} / M_{y}$ is increased, the propagating oxygen wave on the surface "elongates" in the [110] direction (allow me to remind that $\mathrm{O}_{\mathrm{ads}}$ doesn't diffuse over the surface, only $\mathrm{CO}_{\mathrm{ads}}$ !). The $\mathrm{CO}_{\mathrm{ads}}$ diffusion anisotropy effect is especially pronounced in the simulation of spiral oxygen waves on the $\operatorname{Pd}(110)$ surface. The simulation of this kind of spatiotemporal structure is detailed in [34]. In our computational experiment, the isotropic diffusion regime $\left(M_{x} / M_{y}=50 / 50\right)$ was changed to an anisotropic diffusion regime with $M_{x} / M_{y}=80 / 20$. This led to the "elongation" of the spiral oxygen wave along the [110] direction [37, 23], Figure 9. This asymmetric behavior is in good agreement with the experimental observation of spiral waves in this reaction by the PEEM method.
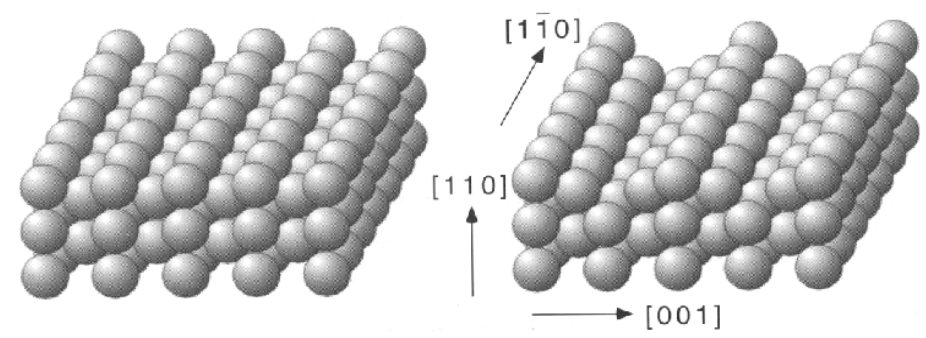

Figure 7. Reconstruction of the $\mathrm{Pd}(110)-(1 \times 1)$ into the $(1 \times 2)$ "missing row" structure caused by oxygen or carbon monoxide adsorption.

Simulation of the $\mathrm{CO}$ oxidation dynamics on $\mathrm{Pd}(110)$ at a low $\mathrm{CO}_{\text {ads }}$ diffusion rate $(\mathrm{M}=20)$ gave somewhat unexpected results $[35,36]$. Decrease of $M$ up to value $M=50$ doesn't change significantly the oscillatory and wave dynamics, but decreasing to value $M=20$ drastically change both the shape of oscillations and the spatiotemporal behavior of simulated surface waves. As in the case of $\mathrm{Pt}(100)$, period and amplitude of oscillations decrease considerably, the dynamic behavior of reaction rate and surface coverages demonstrate the intermittence (oscillatory regime I, Figure 10). During these oscillations oxygen $\left(\mathrm{O}_{\mathrm{ads}}\right)$ is always present on the surface in the form of turbulent spatio-temporal structures (Figure 11a). It is seen from Figure 11a that the whole surface is divided in several islands oscillating with the same period but with a phase shift relative to each other, therefore the reaction rate and coverage's time dependencies demonstrate the intermittence peculiarities. Here one can observe on the surface the spatio-temporal pattern of complicated turbulent shape. The colliding oxygen islands form the spiral-like patterns. Step-by step decrease of oxygen partial pressure (remember, that the values for $\mathrm{O}_{2}$ and $\mathrm{CO}$ adsorption coefficients, $\mathrm{k}_{1}, \mathrm{k}_{2}$, and $\mathrm{k}_{6}\left(\mathrm{~s}^{-1}\right)$, can be treated as the product of the impingement rate $\left(\mathrm{k}_{\mathrm{i}} \times \mathrm{P}_{\mathrm{i}}\right)$ and of the sticking coefficient (S)) leads to the gradual thinning of oxygen travelling waves, Figures 11b-e. 


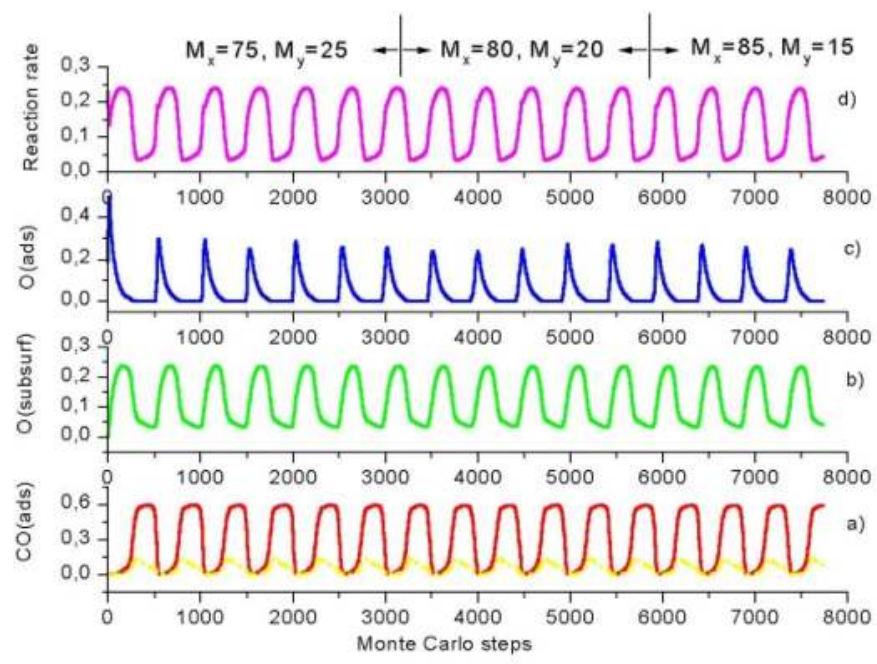

Figure 8. Dynamics of changes in surface coverages $\mathrm{CO}_{\text {ads }}$ (red lines) and $\mathrm{CO}_{\text {ads }} \mathrm{O}_{\text {sub }}$ (yellow lines), $\mathrm{O}_{\text {sub }}$ (green lines), $\mathrm{O}_{\text {ads }}$ (blue lines), and the specific reaction rate at different ratios $M_{x} / M_{y}$.
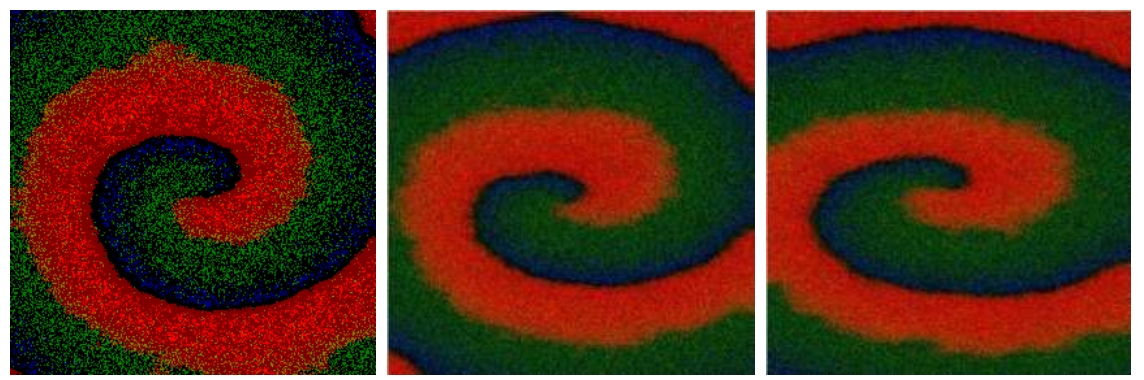

Figure 9. Evolution of the simulated spiral waves [34] in CO oxidation over $\mathrm{Pd}(110)$ after the switching the diffusion intensity $\mathrm{M}$ from isotropic regime $(\mathrm{Mx} / \mathrm{My}=50 / 50)$ to the anisotropic one $(\mathrm{Mx} / \mathrm{My}=80 / 20)$. The designations of adsorbates are the same as for Figure 6.

At low values of $\mathrm{k}_{1}$ (Figure $11 \mathrm{~d}-\mathrm{f}$ ) the long and thin oxygen stripe (or "worm"-like) patterns are formed on the simulated surface, and the clear tendency of turbulent patterns to combine into spirals disappeared at $\mathrm{k}_{1}<0.8$. The amplitude of oscillations diminished with decreasing of $k_{1}$. At last, at $k_{1}=0.71$ (Fig. $11 \mathrm{f}$ ), the oxygen stripe wave vanish slowly from the surface and the system transform to the low reactive state (the surface is predominantly covered by $\mathrm{CO}_{\text {ads }}$ ). 


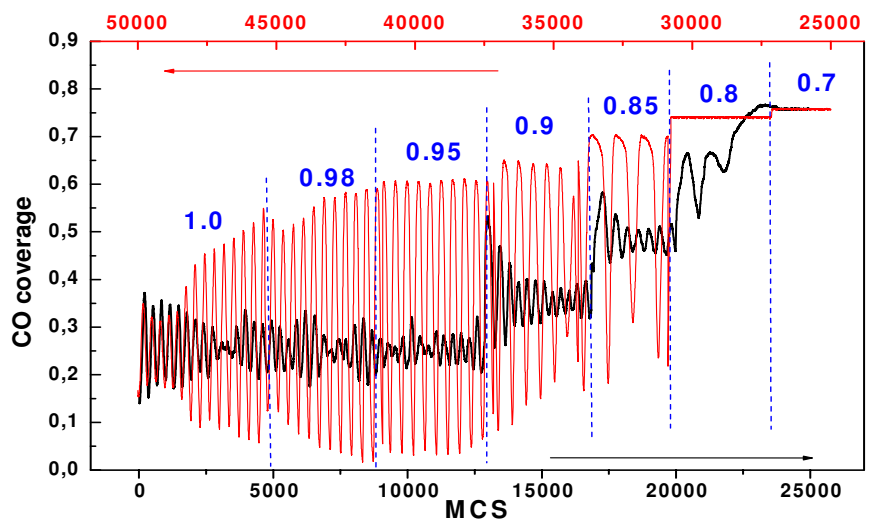

Figure 10. Hysteresis of oscillatory regimes in CO oxidation reaction over $\mathrm{Pd}(110)$ at decreasing $(\rightarrow)$ and increasing $(\leftarrow)$ of oxygen partial pressure $\left(\mathrm{k}_{1}\right)$. Intensity of $\mathrm{CO}_{\text {ads }}$ diffusion $\mathrm{M}=20$.

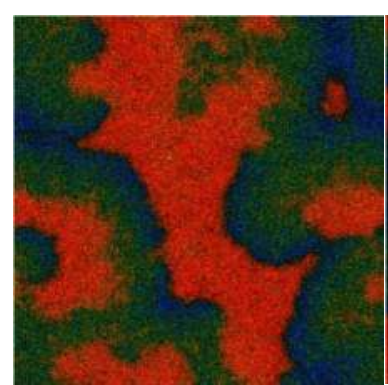

(a)

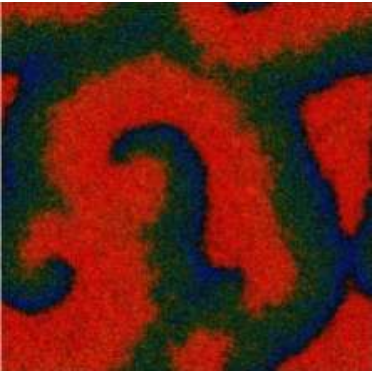

(b)

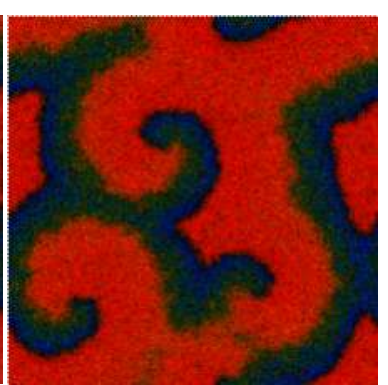

(c)

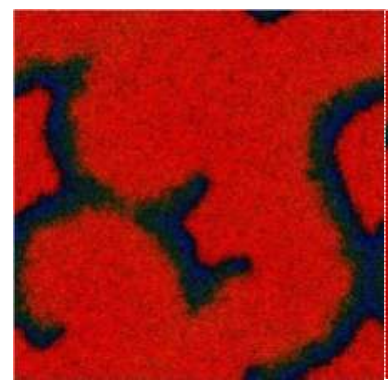

(d)

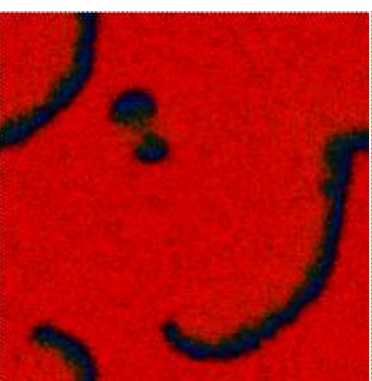

(e)

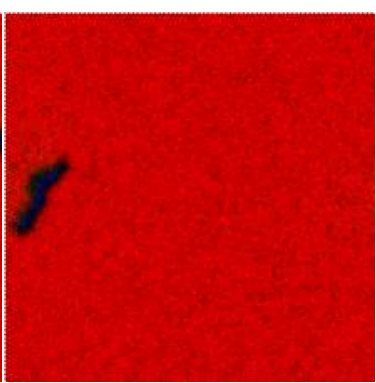

(f)

Figure 11. Typical snapshots reflecting the adsorbate distribution over the surface at step-by-step reducing of $\mathrm{P}\left(\mathrm{O}_{2}\right)$ (or $k_{1}$ ). a) $\mathrm{P}\left(\mathrm{O}_{2}\right)=1$; b) $\mathrm{P}\left(\mathrm{O}_{2}\right)=0.9$; c) $\mathrm{P}\left(\mathrm{O}_{2}\right)=0.85$; d) $\mathrm{P}\left(\mathrm{O}_{2}\right)=0.8$; e) $\mathrm{P}\left(\mathrm{O}_{2}\right)=0.73$; f) $\mathrm{P}\left(\mathrm{O}_{2}\right)=0.71$. Intensity of $\mathrm{CO}_{\text {ads }}$ diffusion $\mathrm{M}=20$. The designations of adsorbates are the same as for Figure 6. 
The reverse increasing of $k_{1}$ leads to hysteresis in oscillatory behavior. The oscillation appears only at $k_{1}=0.85$ via very fast "surface explosion" (Figure $12 \mathrm{a}-\mathrm{h}$ ). It is surprising that the characteristics of oscillations differ drastically from those observed at gradual decreasing of $k_{1}$. Now the amplitude of oscillations in the regime II, Figure 10 (coverage's and reaction rate), is larger than in regime I, and instead of turbulent spiral-like pattern (Figure $11 \mathrm{a}-\mathrm{c}$ ) we observe the alternately change of $\mathrm{O}_{\text {ads }}$ and $\mathrm{CO}_{\text {ads }}$ layers via growing cellular oxygen islands (Figure 12) similar to the case with large diffusion intensity (Figure 6). The interval of existence of these oscillations increased significantly. The simulations at higher lattice size $\mathrm{N}=$ 8000 in the lower boundary of the regime II $\left(\mathrm{k}_{1}=0.83\right)$ gave the "target"-like structures, which were observed experimentally [39], Figure 13.

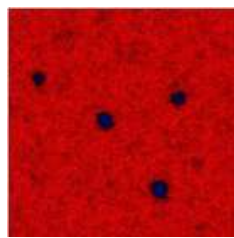

(a)

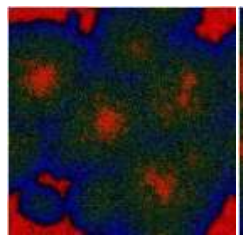

(e)

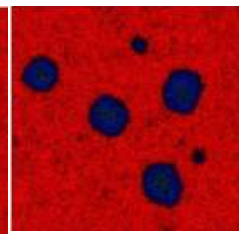

(b)

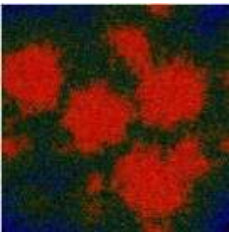

(f)

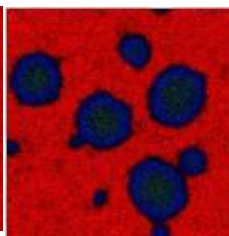

(c)

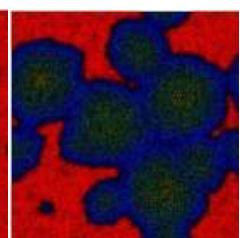

(d)

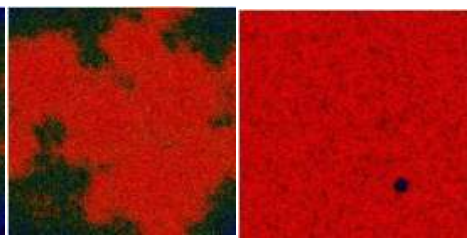

(g)

(h)

Figure 12. The snapshots illustrating the rise of oscillations (via surface explosion) at inverse step-by-step increasing of $k_{1}\left(k_{1}=0.85\right)$. The time interval between frames is $50 \mathrm{MC}$ steps.

Only at $\mathrm{k}_{1}=1$ occurs the transformation from the regime II to the regime I, Figure 10 , - we observe again the turbulent patterns over the surface (Fig. 11 a). In the cases discussed above we perform the simulation experiments with constant $\mathrm{P}(\mathrm{CO})$, i.e., constant $\mathrm{k}_{2}$ and $\mathrm{k}_{6}$, changing over and back the $\mathrm{O}_{2}$ partial pressure $\left(\mathrm{k}_{1}\right)$. When we performed the simulations with constant $\mathrm{k}_{1}=1 \mathrm{~s}^{-1}, \mathrm{M}=20$, and changing step-wise $\mathrm{k}_{2}$ and $\mathrm{k}_{6}$ (i.e., $\mathrm{P}(\mathrm{CO})$ ) from 0.5 to 1.5 and back, we also obtained the hysteresis in oscillatory regime with similar spatiotemporal patterns on the surface.

It has been found in experiments that the different oscillatory windows could exist in the parameter space of the particular system, e.g., CO oxidation over Pt (100) [40], i.e., at different parameters (temperature and $\mathrm{CO} / \mathrm{O}_{2}$ ratio) two regions has been found at a constant total pressure where the rate oscillations and spatiotemporal formations have been observed. In our case two different oscillatory regimes with discriminate spatiotemporal dynamics have been revealed in simulations in the same variation interval of $\mathrm{P}\left(\mathrm{O}_{2}\right)$, Figure 10. That means, that at the same value of the key parameter (e.g., $\left.\mathrm{k}_{1}=0.85\right)$ two different «cycles» 
could exist. The shape of «integral» oscillations and spatio-temporal patterns depends on the dynamic prehistory (shape-memory effect).

The interval of existence of oscillatory regime II is quite large: $0.98>\mathrm{k}_{1}>0.82$. Increasing $\mathrm{k}_{1}$ in this interval leads to the increasing of the amplitude and decreasing of the period of oscillations. At low bound of this interval (i.e., at $\mathrm{k}_{1}=0.83$ ) the target structures of growing oxygen islands has been observed (Figure 13) - during the oxygen island propagation $\mathrm{CO}$ have the possibility to adsorb into its centre. In this case the period of oscillations increased significantly ( 2000 MCS).

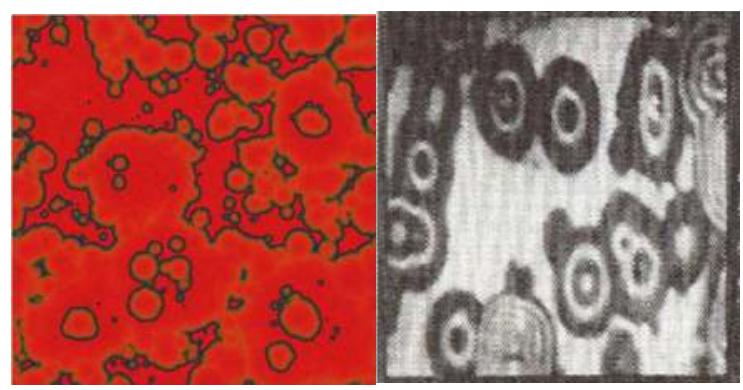

(a)

(b)

Figure 13. a) Simulated "target" structures at the bottom of the oscillatory regime $\left.I I\left(k_{1}=0.83\right), M=20, N=8000 . b\right)$ adsorbed oxygen and carbon monoxide structures experimentally observed on the Pt(100) by Photo Emission Electron Microscopy (PEEM) [39]. Bright regions $-\mathrm{CO}_{\text {ads }}$ dark regions $-\mathrm{O}_{\mathrm{ads}}$.

Figure 10 illustrates the whole scenario of $\mathrm{k}_{1}$ change during our simulation experiments, exemplified by $\mathrm{CO}_{\mathrm{ads}}$ dynamics.

\section{Conclusion}

As was stated in our review [41] published twenty years ago - "One may anticipate, that as early as the end of this decade, experimentally produced documentary movies "From the Life of Molecules" will be systematically compared with those obtained by means of computer experiments (e.g., by Monte Carlo method)". Now we can see, that these hopes began to justify (at least, partly):

It was revealed from the simulations that there exists a narrow reaction zone with maximal local rate of reaction when an oxygen wave propagates over the surface, and this was confirmed by APFIM data.

Accounting the anisotropy of the $\mathrm{Pd}(110)$ single crystal has no effect on the oscillation period and amplitude, but leads to elliptic oxygen patterns on the surface. The formation of these patterns is confirmed by surface space-resolved methods (e.g., PEEM). 
A wide variety of chemical waves (cellular and turbulent patterns, spirals, rings, and strips) can be obtained by varying the parameters of the computational experiment. All of these patterns were actually observed in experimental studies of the oscillatory dynamics of catalytic reactions.

\section{Acknowledgements}

This work was partly supported by Russian Fund for Basic Research, Grant \# 12-03-00766a and by Siberian Branch of Russian Academy of Sciences (Interdisciplinary Integration Project \# 47).

\section{Author details}

Vladimir I. Elokhin*

Address all correspondence to: elokhin@catalysis.ru

Boreskov Institute of Catalysis, Siberian Branch of Russian Academy of Sciences and Novosibirsk State University, Novosibirsk, Russian Federation

\section{References}

[1] Imbihl R. Oscillatory reactions at single-crystal surfaces. Progr. Surf. Sci. 1993; 44185.

[2] Van Hove M.A., Somorjai G.A. Adsorption and adsorbate-induced restructuring: a LEED perspective. Surf. Sci. 1994; 299/300(1) 487-501.

[3] Nørskov J.K. Theory of adsorption and adsobate-induced restructuring. Surface Sci. 1994; 299/300(1) 690-705.

[4] Lapujoulade J. The roughening of metal surfaces. Surf. Sci. Rep. 1994; 20(4) 191- 294.

[5] Bracco J. Thermal roughening of the (110) surfaces of unreconstructed f.c.c. metals. Phys. Low-Dim. Struct. 1994; 8 1-22.

[6] Landau D.P., Binder K. A guide to Monte-Carlo simulations in statistical physics. Cambridge University Press: Cambridge, 2000.

[7] Temel B., Meskine H., Reuter K., Scheffler M., Metui H. Does phenomenological kinetics provide an adequate description of heterogeneous catalytic reactions? J. Chem. Phys. 2007; 126204711. 
[8] Sharifulina A., Elokhin V. Simulation of heterogeneous catalytic reaction by asynchronous cellular automata on multicomputer. Lectures Notes of Computer Science. 2011; 6873 204-209.

[9] Slinko M.G., Slinko M.M. Self-oscillations of heterogeneous catalytic reaction rates. Catal. Rev. Sci. Eng. 1978; 17 119-153.

[10] Razon L.F., Schmitz R.A. Intrinsically unstable behavior during the oxidation of carbon monoxide on platinum. Catal. Rev. Sci. Eng. 1986; 28 89-164.

[11] Ertl G. Oscillatory catalytic reactions on single-crystal surfaces. Adv. Catal. 1990; 37 213-277.

[12] Yablonskii G.S., Bykov V.I., Gorban' A.N., Elokhin V.I. Kinetic Models of Catalytic Reactions. In: Compton, R.G. (ed.) Comprehensive Chemical Kinetics, vol. 32, Amsterdam: Elsevier, 1991, chapt. 5 and 6.

[13] Schüth F., Henry B.E., Schmidt L.D. Oscillatory reactions in heterogeneous catalysis. Adv. Catal. 1990; 39 51-127.

[14] Eiswirth M., Ertl G. Pattern formation on catalytic surfaces. In: Kapral R., Showalter K. (eds.) Chemical Waves and Patterns, Understanding Chemical Reactivity, vol. 10, Dordrecht: Kluwer, 1994, p. 447-489.

[15] Slinko M.M., Jaeger N.I. Oscillating Heterogeneous Catalytic Systems. In: Delmon B., Yates J.T. (eds.) Studies in Surface Science and Catalysis, vol. 86, Amsterdam: Elsevier, 1994.

[16] Imbihl R., Ertl G. Oscillatory kinetics in heterogeneous catalysis. Chem. Rev. 1995; 95 697-733.

[17] Ertl G. Dynamics of reactions at surfaces. Adv. Catal. 2000; 45 1-69.

[18] Cobden P.D., Janssen N.M.H., van Breugel Y., Nieuwenhuys, B.E. Non-linear behavior in the NO- $\mathrm{H}_{2}$ reaction over single crystals and field emitters of some Pt-group metals. Faraday Discuss. 1996; 105 57-72.

[19] Appendix: Oscillatory Heterogeneous Catalytic Systems. Catal. Today. 2005; 105 I-II.

[20] Zhdanov V.P. Monte-Carlo simulation of oscillations, chaos and pattern formation in heterogeneous catalytic reactions. Surf. Sci. Rep. 2002; 45; 231-326.

[21] Latkin E.I., Elokhin V.I., Gorodetskii V.V. Monte Carlo model of oscillatory CO oxidation having regard to the change of catalytic properties due to the adsorbate induced Pt(100) structural transformation. J. Molec. Catal. A: Chemical. 2001; 166(1) 23-30.

[22] Elokhin V.I., Gorodetskii V.V. Atomic scale imaging of oscillations and chemical waves at catalytic surface reactions: Experimental and statistical lattice models. In: A.M. Spasic, J.-P. Hsu, (eds.) Finely Dispersed Particles: Micro-, Nano-, and Atto-En- 
gineering. Surfactant Science, vol. 130. Taylor \& Francis, CRS Press: New York, 2005; Chapter 7, 159-189.

[23] Gorodetskii V.V., Elokhin V.I., Bakker J.W., Nieuwenhuys B.E. Field Electron and Field Ion Microscopy studies of chemical wave propagation in oscillatory reactions on platinum group metals. Catalysis Today 2005; 105(2) 183-205.

[24] Elokhin V.I., Matveev A.V., Kovalyov E.V., Gorodetskii V.V. From single crystals to supported nanoparticles in oscillatory behavior of $\mathrm{CO}+\mathrm{O}_{2}$ reaction on platinum and palladium surfaces: Experiment and stochastic models. Chem. Eng. Journal 2009; 154(1-3) 94-106.

[25] Gruyters M., Ali T., King D.A. Theoretical inquiry into the microscopic origin of the oscillatory CO oxidation reaction on Pt(100). J. Phys. Chem. 1996; 100 14417-14423.

[26] Imbihl R., Cox M.P., Ertl G., Müller H., Brenig W. Kinetic oscillations in the catalytic CO oxidation on Pt(110): Theory. J. Chem. Phys. 1985; 83 1578-1587.

[27] Gorodetskii V.V., Drachsel, W. Kinetic oscillations and surface waves in catalytic CO $+\mathrm{O}_{2}$ reaction on Pt surface: FEM, FIM and HREELS studies. Appl. Catal., A: Gen. $1999 ; 188,267-275$.

[28] Gorodetskii V.V., Matveev A.V., Podgornov E.A., Zaera, F. Study of low-temperature reaction between $\mathrm{CO}$ and $\mathrm{O}_{2}$ over Pd and Pt surfaces. Top. Catal. 2005; 32(1) 17-28.

[29] Sales B.S., Turner J.B., Maple, M.B. Oscillatory oxidation of CO over Pt, Pd and Ir catalysts: Theory. Surf. Sci., 1982; 114 381-394.

[30] Latkin E.I., Elokhin V.I., Matveev A.V., Gorodetskii V.V. The role of subsurface oxygen in oscillatory behaviour of $\mathrm{CO}+\mathrm{O}_{2}$ reaction over Pd metal catalysts: Monte Carlo model. J. Molec. Catal. A: Chemical 2000; 158(1) 161-166.

[31] Vishnevskii A.L., Latkin E.I., Elokhin V.I. Autowaves on catalyst surface caused by carbon monoxide oxidation kinetics: Imitation model. Surf. Rev. Lett. 1995; 2 459-469.

[32] Elokhin V., Kalgin K., Kovalyov E., Matveev A., Gorodetskii V. Specificity of oscillation performance over the flexible surfaces of the metal nanoparticles: Monte-Carlo approach. XIX International Conference on Chemical Reactors "ChemReactor-19", Vienna, Austria, September 5-9, 2010. Abstracts, OP-I-5, pp. 45-46.

[33] Elokhin V.I., Latkin E.I. Statistical model of oscillatory and wave phenomena on a catalyst surface in CO oxidation. Dokl. Akad. Nauk, 1995, vol. 344, p. 56-61.

[34] Latkin E.I., Elokhin V.I., Gorodetskii V.V. Spiral concentration waves in the MonteCarlo model of $\mathrm{CO}$ oxidation over $\mathrm{Pd}(110)$ caused by synchronization via $\mathrm{CO}_{\text {ads }}$ diffusion between separate parts of catalytic surface. Chem. Eng. Journal, 2003; 91(2-3) 123-131.

[35] Matveev A.V., Latkin E.I., Elokhin V.I., Gorodetskii V.V. Turbulent and stripes wave patterns caused by limited $\mathrm{CO}_{\text {ads }}$ diffusion during $\mathrm{CO}$ oxidation over $\operatorname{Pd}(110)$ surface: Kinetic Monte-Carlo studies. Chem. Eng. Journal, 2005, V. 107, N 1, pp. 181-189. 
[36] Elokhin V., Matveev A., Gorodetskii V., Latkin E. Hysteresis in Oscillatory Behaviour in CO Oxidation Reaction over Pd(110) Revealed by Asynchronous Cellular Automata Simulation. Lectures Notes of Computer Science. 2007; 4671 401-409.

[37] Matveev A.V., Latkin E.I., Elokhin V.I., Gorodetskii V.V. Manifestation of the adsorbed $\mathrm{CO}$ diffusion anisotropy caused by the structure properties of the $\operatorname{Pd}(110)-(1 \times 2)$ surface on the oscillatory behavior during $\mathrm{CO}$ oxidation reaction - Monte-Carlo model. Chemistry for Sustainable Development. 2003; 11(1) 173-180.

[38] Elokhin V.I., Matveev A.V., Kovalyov E.V., Gorodetskii V.V. From single crystals to supported nanoparticles in oscillatory behavior of $\mathrm{CO}+\mathrm{O}_{2}$ reaction on platinum and palladium surfaces: Experiment and stochastic models. Chem. Eng. Journal. 2009; 154(1-3) 94-106.

[39] Jakubith S., Rotermund H.H., Engel W., von Oertzen A., Ertl G. Spatio-temporal concentration patterns in a surface reaction: Propagating and standing waves, rotating spirals, and turbulence. Phys. Rev. Lett. 1990; 65 3013-3016.

[40] Lauterbach J., Bonilla G., Fletcher T.D. Non-linear phenomena during CO oxidation in the mbar pressure range: a comparison between $\mathrm{Pt} / \mathrm{SiO}_{2}$ and $\mathrm{Pt}(110)$. Chem. Eng. Sci. 1999; 54 4501-4512.

[41] Yablonskii G.S., Elokhin V.I. Kinetic models of heterogeneous catalysis. In: Thomas J.M., Zamaraev K.I. (eds.) Perspectives in Catalysis. Blackwell Scientific Publications. Oxford. 1992. pp. 191-249 